\title{
Study of microextrusion printing for enlarging electrode-electrolyte interfacial area in anode-supported SOFCs
}

\section{$\operatorname{AUTHOR(S):~}$}

Seo, Haewon; Nishi, Taisei; Kishimoto, Masashi; Ding, Changsheng; Iwai, Hiroshi; Saito, Motohiro; Yoshida, Hideo

\section{CITATION:}

Seo, Haewon ... [et al]. Study of microextrusion printing for enlarging electrode-electrolyte interfacial area in anode-supported SOFCs. ECS Transactions 2019, 91(1): 1923-1931

\section{ISSUE DATE:}

2019-07-10

URL:

http://hdl.handle.net/2433/250823

\section{RIGHT:}

(C) The Electrochemical Society, Inc. 2019. All rights reserved. Except as provided under U.S. copyright law, this work may not be reproduced, resold, distributed, or modified without the express permission of The Electrochemical Society (ECS). The archival version of this work was published in [ECS Transactions, 91(1), 1923-1931]; この論文は出版社版であ りません。引用の際には出版社版をご確認じ利用ください。;This is not the published version. Please cite only the published version. 


\title{
Study of Microextrusion Printing for Enlarging Electrode-Electrolyte Interfacial Area in Anode-supported SOFCs
}

\author{
Haewon Seo, Taisei Nishi, Masashi Kishimoto, Changsheng Ding, Hiroshi Iwai, \\ Motohiro Saito, and Hideo Yoshida
}

Department of Aeronautics and Astronautics, Kyoto University, Kyoto 615-8540, Japan

\begin{abstract}
Anode ridge structures are fabricated by printing anode pastes having different rheological properties to increase the electrodeelectrolyte interfacial area in anode-supported solid oxide fuel cells. Homogeneous anode pastes are prepared by varying solid loadings, then their rheological characteristics are evaluated. It is confirmed that the shear stress at the same shear rate increases with increasing solid loading. The prepared pastes are printed onto flat anode substrates and then the width and height of the printed pastes are observed before and after drying and after sintering. As increasing solid loading in the paste, not only the width and height become smaller and larger, respectively, but also the shrinkage rate of the aspect ratio becomes smaller. Consequently, a large extension of the interfacial area of about $285 \%$ is obtained by printing the paste with the solid loading of $80 \%$.
\end{abstract}

\section{Introduction}

Recently, anode-supported solid oxide fuel cells (SOFCs) are being practically used owing to their high electrochemical performance. Since they are generally designed with a thin electrolyte film of about $10 \mu \mathrm{m}$, the ohmic loss attributed to the electrolyte can be greatly reduced. This advantage enables the operating temperature to be decreased for the longterm stability of SOFC systems. To further improve the performance of the anodesupported SOFCs at low temperatures $\left(600-800^{\circ} \mathrm{C}\right)$, however, overpotentials attributed to the electrochemical reaction need to be decreased. For this purpose, several researchers have been focusing on increasing electrode-electrolyte interfacial area in mesoscale (10 $100 \mu \mathrm{m})$ to improve the electrochemical performance (1-7) since the electrochemical reaction mainly occurs at a region within about $20 \mu \mathrm{m}$ from the electrode-electrolyte interface (8-11).

In our previous study (5), a microextrusion printing method which extrudes a highly viscoelastic paste onto a solid substrate was used for increasing the electrode-electrolyte interfacial area of anode-supported SOFCs to improve their electrochemical performance. Anode-supported SOFCs having corrugated structures were fabricated by printing a NiOyttria-stabilized zirconia (YSZ) anode paste in a line shape onto the surface of flat anode substrates. Also, it was confirmed that the cell performance was improved with increasing the interfacial area under the same operating conditions. For instance, the terminal voltage at the current density of $0.3 \mathrm{~A} \mathrm{~cm}^{-2}$ at $600^{\circ} \mathrm{C}$ was increased by $48 \%$ in a patterned cell whose interfacial enlargement factor was 1.20 compared with that of a flat cell. However, since the width and height of the anode ridge structures after sintering were $c a$. 200 and $c a$. 
$40 \mu \mathrm{m}$, respectively, their aspect ratio (ratio of width to height) was only 0.19 , which led to the relatively small interfacial enlargement factor. Therefore, it is expected that further performance improvement of anode-supported SOFCs can be achieved by increasing the aspect ratio of the ridge structures, and thereby increasing the reaction region.

The aim of this study is to fabricate anode ridge structures with an increased aspect ratio by controlling the rheological properties of anode pastes used for microextrusion printing. NiO-YSZ anode pastes are prepared with different solid loading and then their rheological properties are measured. After that, the measurement data are fitted to the Herschel-Bulkley fluid model, one of the non-Newtonian fluid models. The prepared anode pastes are printed in a line shape onto flat anode substrates to make anode ridge structures. To investigate the correlation between the structural geometries and the viscoelasticity of the anode pastes, the width and height of the anode ridge structures are measured using a 3D surface profile measurement system. Then, their structural changes in the process of drying and sintering pastes are compared. Finally, a cross section of the anode ridge structures after sintering is observed using a scanning electron microscopy (SEM).

\section{Experimental}

\section{Preparation of the NiO-YSZ Anode Paste}

To investigate the effect of the rheological properties of the anode pastes on the anode ridge structures, the anode pastes with varying solid loadings (the amount of mixture powder in an anode paste) were prepared as extrusion materials. The anode pastes were composed of NiO-YSZ mixture powder and a commercial terpineol-based binder (VEH, Nexceris, LLC., USA). 66 wt\% NiO powder (FUJIFILM Wako Pure Chemical Corp., Japan) and $34 \mathrm{wt} \%$ YSZ powder (TZ-8Y, Tosoh Corp., Japan) were mixed by planetary ball milling in isopropanol with zirconia ball media $(\phi 4.0 \mathrm{~mm})$ at $450 \mathrm{rpm}$ for $1 \mathrm{~h}$. After the isopropanol was completely dried, the mixed powder was sieved with $53 \mu \mathrm{m}$ mesh. Then, the powder was added to the binder with various weight ratio values $(75,78$, and 80 wt\% in total, abbreviated as P75, P78, and P80, respectively), then the mixture was stirred at $2000 \mathrm{rpm}$ for $30 \mathrm{~min}$.

\section{Measurement of the Rheological Properties}

The rheological properties of the prepared anode pastes were measured using a rotational double coaxial cylinder viscometer (Viscolead ADV, Fungilab S.A., Spain), which consists of two main cylinders: an inner cylinder and an outer cylinder, as schematically shown in Figure 1. The anode paste was filled into a gap between the two cylinders, then its apparent viscosity was calculated from the measurement of the torque transferred between both cylinders via the paste. The measurement was conducted under various rotation speeds in the range from 0.3 to $100 \mathrm{rpm}$ using the inner cylinder (spindle) with a diameter of $7.6 \mathrm{~mm}$. Also, a thermostatic water bath was used to keep the temperature at $27^{\circ} \mathrm{C}$.

To evaluate the rheological properties of the anode pastes, the measurement data were characterized using the Herschel-Bulkley model (12). This model is one of the non- 
Newtonian fluid models which combines yield shear stress and shear-thinning behavior in a fluid, expressed as

$$
\tau=\tau_{0}+K \dot{\gamma}^{n}
$$

where $\tau$ is the shear stress, $\tau_{0}$ is the yield shear stress, $K$ is the consistency coefficient, $\dot{\gamma}$ is the shear rate and $n$ is the flow behavior index. According to the literature (13), in the case of polymer melts and solutions, the value of $n$ is in the range of about $0.3-0.7$ depending on the molecular weight and concentration of the polymer. Also, its value is about $0.1-0.15$ for fine particles suspension. Moreover, the closer the value of $n$ is to zero, the higher pseudoplasticity.

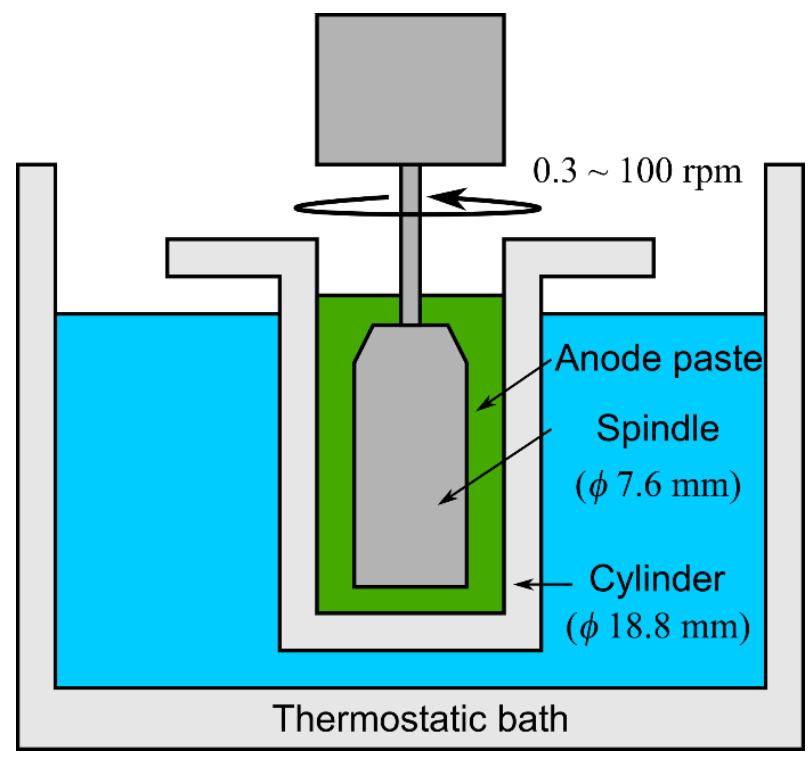

Figure 1. Schematic view of the rotational double coaxial cylinder viscometer.

\section{Fabrication of the Anode Ridge Structure}

To fabricate the anode ridge structures, the anode pastes were printed onto the flat anode substrates prepared using the uniaxial hand-pressing method. Mixed powder for the substrates was composed of $80 \mathrm{wt} \% \mathrm{NiO}-\mathrm{YSZ}$ powder (NiO:YSZ $=66: 34 \mathrm{wt} \%)$ and a 20 wt\% pore former (Asahi\#15, Asahi Carbon Co. Ltd., Japan). The powder was pressed at $60 \mathrm{MPa}$ for $1 \mathrm{~min}$, then was presintered at $1250^{\circ} \mathrm{C}$ for $2 \mathrm{~h}$. A $260 \mathrm{~g}$ porous zirconia plate was placed during the presintering process to prevent substrate warpage.

Microextrusion printing was conducted using a combined system of precision $x-y$ stages with a syringe pump as shown in Figure 2(a). The anode paste was put into a gastight syringe until a small amount of the paste came out of the syringe to remove the remaining air. Then, a micro-nozzle tip (Nordson Corp., USA) with an inner diameter of $150 \mu \mathrm{m}$ was attached to the end of the syringe. After that, the syringe was vertically fixed to the syringe pump. The anode substrate was fixed onto the precision stages. The gap between the nozzle tip and the substrate was adjusted to about $100 \mu \mathrm{m}$ using a precision $z$ stage. Thereafter, the printing process was conducted at a stage speed of $10 \mathrm{~mm} \mathrm{~s}^{-1}$, an applied flow rate of $10 \mu \mathrm{L} \mathrm{min}{ }^{-1}$, and a printing interval of $400 \mu \mathrm{m}$. The printed pastes were dried at room temperature $\left(25^{\circ} \mathrm{C}\right)$, followed by sintering at $1400^{\circ} \mathrm{C}$ for $5 \mathrm{~h}$. 
(a)

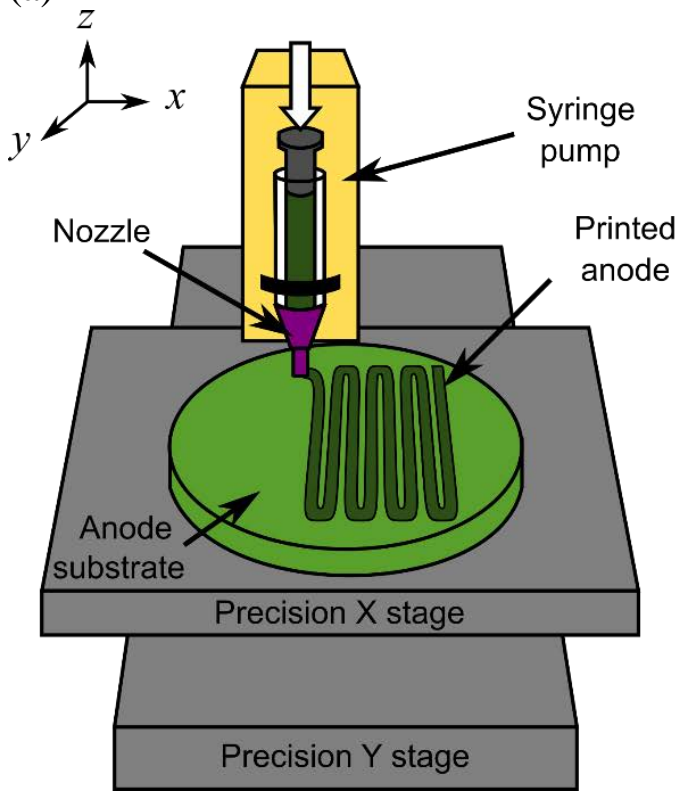

(b)

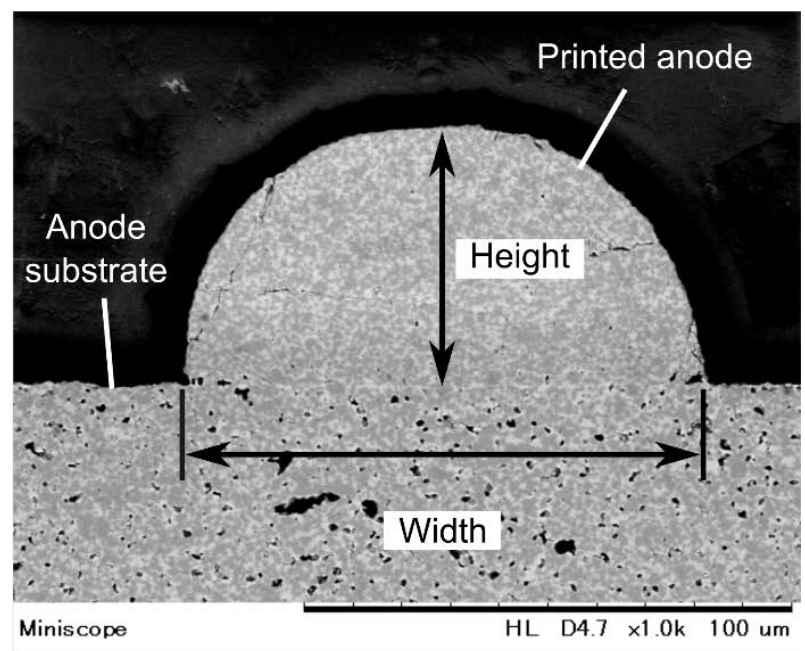

Figure 2. (a) Schematic view of the micro-extrusion process on anode substrate and (b) an example of the cross-sectional SEM image of the anode ridge structure.

To compare the structural changes of the anode ridge structures, their width and height before and after drying, and after sintering were measured using a 3D surface profile measurement system (VR-3100, Keyence Corp., Japan). Also, the cross-section of the ridge structures after sintering was observed using an SEM (Miniscope TM3000, Hitachi Ltd., Japan). By using the SEM images (Figure 2(b)), the width and height were measured using the open-source image processing program "Image J". Then, the enlargement factor defined as the ratio of the arc length to the width (contact length between the substrate and the ridge structure) was evaluated.

\section{Results and Discussion}

\section{$\underline{\text { Rheological Properties of the Anode Pastes }}$}

Figure 3 shows the shear stress curves of the anode pastes as a function of the shear rate. It is confirmed that the shear stress increases as the shear rate, as well as that it possesses the yield shear stress obtained as the vertical intercept. These curves show that each anode paste is a yield pseudoplastic material. Also, at the same shear rate, the shear stress is higher with increasing the solid loading in the anode paste. This indicates that the flow of the liquid phase (binder) is more likely to be inhibited by increasing the solid phase (mixed powder) in the paste, which leads to high apparent viscosity of the paste. Solid lines in this graph represent the fitted results of the measurement data (scatter plot) to the Herschel-Bulkley fluid model. The fitted values of the rheological properties of the anode pastes are summarized in Table I. The modeled values show good agreement with the measured data. The yield shear stress $\tau_{0}$ correlated to the viscoelasticity of the fluid increases with increasing the solid loading. Also, the flow behavior index $n$ in the pastes are in the range of $0.39-0.46$, which indicates that each paste has high pseudoplasticity. 


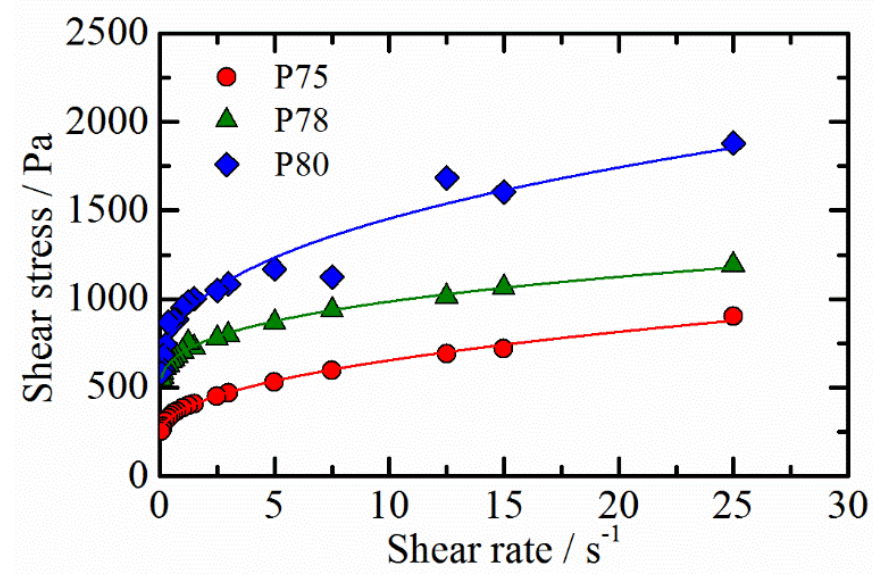

Figure 3. Shear stress curves of NiO-YSZ anode pastes as a function of shear rate.

TABLE I. Fitted parameters of the anode pastes in the Herschel-Bulkley model.

\begin{tabular}{ccccc}
\hline Anode paste & $\begin{array}{c}\text { Yield shear } \\
\text { stress } \\
\boldsymbol{\tau}_{\mathbf{0}}[\mathbf{P a}]\end{array}$ & $\begin{array}{c}\text { Consistency } \\
\text { coefficient } \\
\boldsymbol{K}\left[\mathbf{P a ~ s}^{\boldsymbol{n}}\right]\end{array}$ & $\begin{array}{c}\text { Flow behavior } \\
\text { index } \\
\boldsymbol{n}[-]\end{array}$ & $\boldsymbol{R}^{\mathbf{2}}$ \\
\hline P75 & 224.11 & 150.05 & 0.46 & 0.995 \\
P78 & 452.53 & 245.51 & 0.34 & 0.995 \\
P80 & 514.08 & 385.81 & 0.39 & 0.943 \\
\hline
\end{tabular}

Although $n$ does not show linearity with the solid loading, however, it is observed that its values in P78 and P80 are smaller than that in P75. Note that the consistency coefficient $K$ cannot be compared since its unit depends on the value of the flow behavior index $n$.

\section{Correlation between the Structural Geometries and the Rheological Properties}

Figure 4 shows the width, height, and aspect ratio of the anode ridge structures before and after drying, and after sintering. The width (Figure 4(a)) and height (Figure 4(b)) of the printed pastes become smaller and larger, respectively, with increasing the solid loading. This leads to the increase in the aspect ratio as shown in Figure 4(c). For instance, the average width and average height of the ridge structures before drying are 212 and 76.0 $\mu \mathrm{m}$ in P75, 181 and $87.9 \mu \mathrm{m}$ in P78, and 121 and $121 \mu \mathrm{m}$ in P80, respectively. Thereby, the values of the aspect ratio are 0.36 in P75, 0.49 in P78, and 1.0 in P80. It is considered that the increase in the shear stress (or the apparent viscosity) of the paste with increasing the solid loading leads to a high aspect ratio of the printed paste. By comparing the structural geometries before drying with those after drying, it is confirmed that the decrease in the height is larger than that in the width so that the aspect ratio decreases. The reduction of both the width and height is mainly caused by the evaporation of the binder inside the paste. Also, in the process of drying paste, the decrease in the aspect ratio becomes smaller with increasing the solid loading. Specifically, the aspect ratio in P75 is decreased by 37\% (0.36 to 0.23$)$, whereas those in P78 and P80 are $19 \%$ (0.49 to 0.39$)$ and $0.35 \%$ (1.0 to 0.99), respectively. This is caused by the fact that the volumetric ratio of the binder is smaller with increasing the solid loading. Moreover, the anode ridge structures shrink after sintering, but the aspect ratio after sintering scarcely changes. This indicates that the dried ridge structures can keep their aspect ratio during the heat treatment. From the above results, 
it is demonstrated that the high aspect ratio is obtained using the anode paste with high viscoelasticity.

Figure 5 shows the cross-sectional SEM images of the anode ridge structures after sintering. The width and height are measured as 160 and $37 \mu \mathrm{m}$ in P75, 147 and $56 \mu \mathrm{m}$ in P78, and 60 and $82 \mu \mathrm{m}$ in P80, respectively. Note that, however, the measured width in P80 using the 3D surface profile measurement system shown in Figure 4(a) (ca. $86 \mu \mathrm{m}$ ) is much larger than the actual width (contact length between the substrate and the ridge structure). This is because the ridge structures were observed from above them so that the largest width were measured. The enlargement factor can be calculated as 1.25 in P75, 1.47 in P78, and 3.85 in P80, respectively. Therefore, it can be concluded that the aspect ratio of the anode ridge structures becomes higher with increasing the solid loading in the anode paste, resulting in a large extension of the interfacial area between the electrode and electrolyte. Also, it is expected to achieve the high electrochemical performance of an anode-supported SOFC whose anode ridge structures are fabricated by printing the paste "P80". This is our future study.

(a)

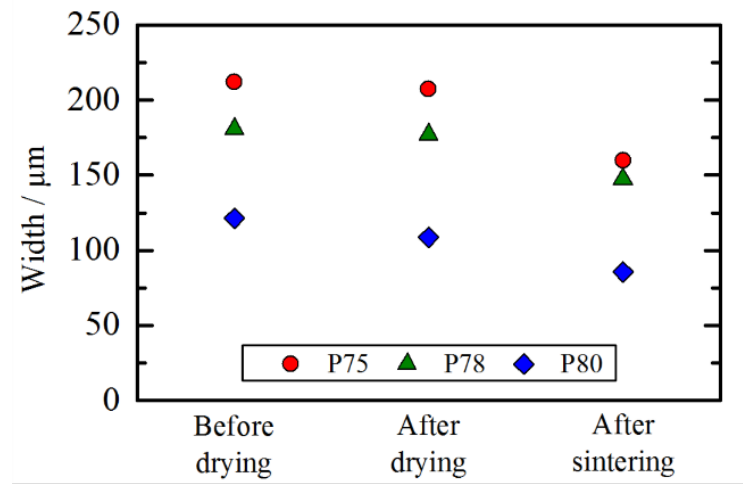

(c)

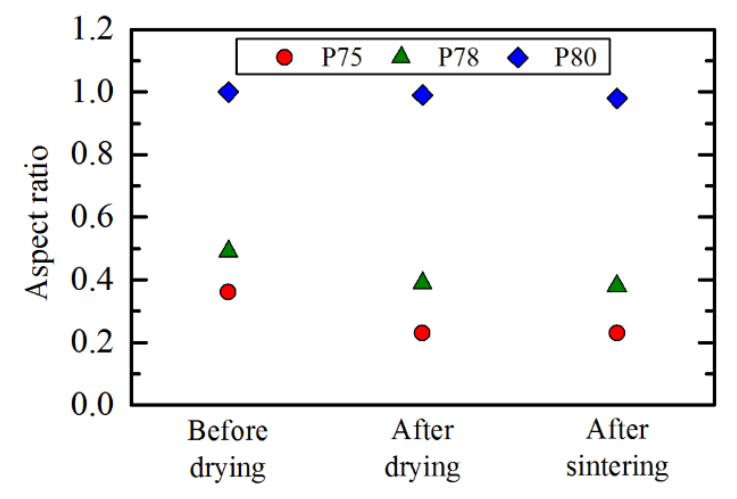

(b)

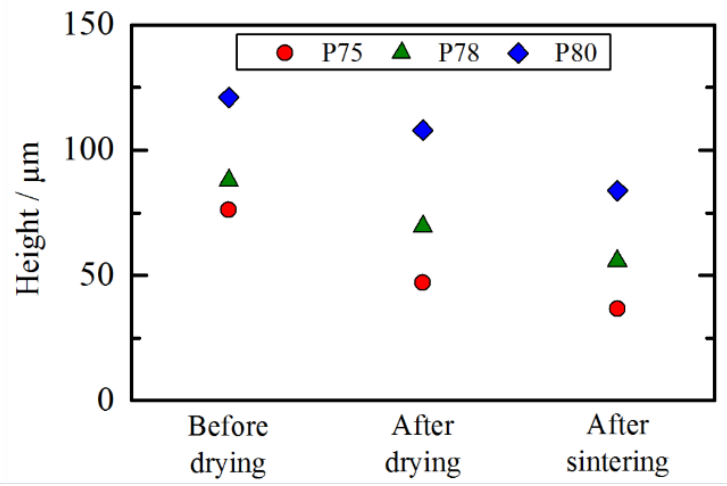

Figure 4. Comparison of (a) width, (b) height, and (c) aspect ratio of anode ridge structures before and after drying, and after sintering. 


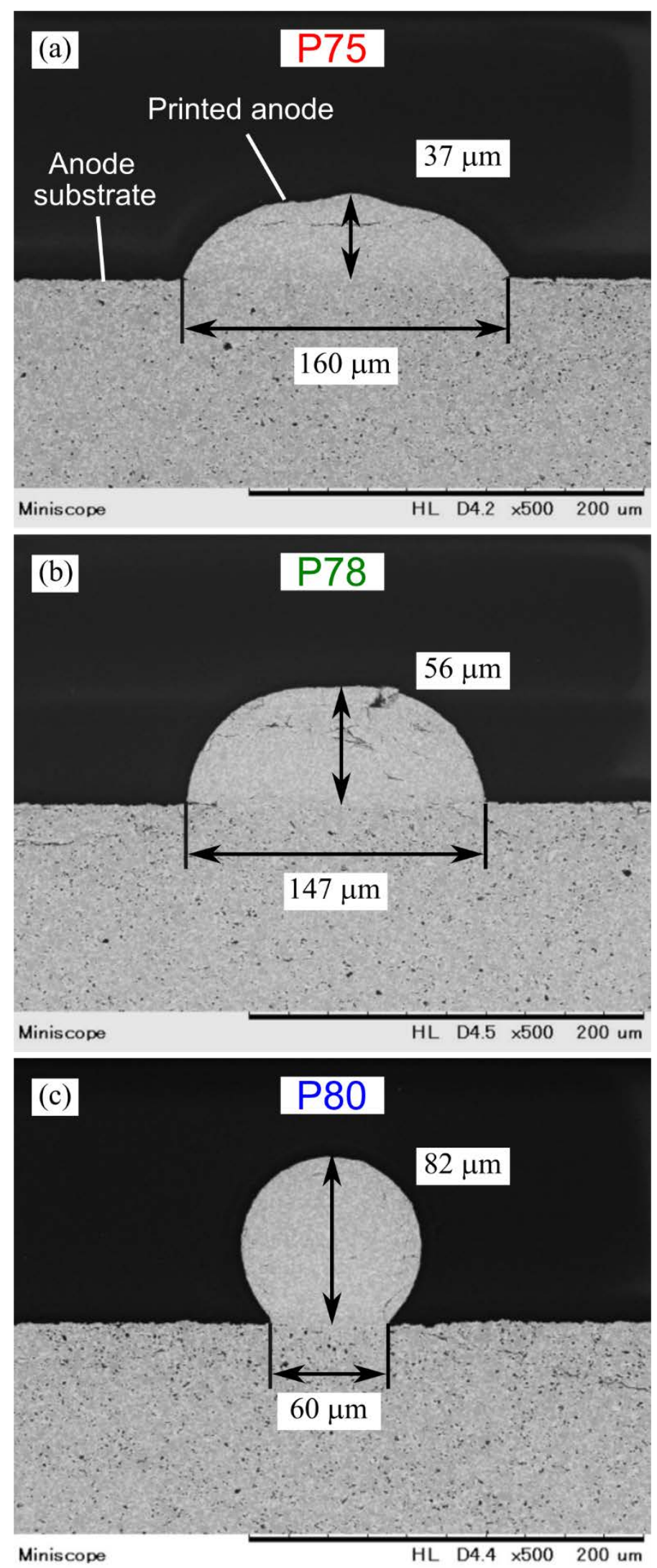

Figure 5. Cross-sectional SEM images of (a) P75, (b) P78, and (c) P80 after sintering. 


\section{Conclusions}

Anode ridge structures were fabricated by printing NiO-YSZ anode pastes with different solid loadings onto flat anode substrates. The rheological properties of the anode pastes were measured to investigate the correlation between their viscoelasticity and the structural geometries of the anode ridge structures after printing. By fitting to the HerschelBulkley fluid model, the measurement data showed good agreement with the model. Also, it was found that the yield shear stress significantly increased with increasing the solid loading, while the shear-thinning behavior was not correlated with the solid loading. The anode ridge structures were then fabricated by printing each anode paste and their structural changes in the drying and sintering process were observed. The width and height of the anode ridge structures after printing became smaller and larger, respectively, with increasing the solid loading. This led to the increase in the aspect ratio of the anode ridge structures since the viscoelasticity of the paste increased. The aspect ratio decreased after drying, whereas it almost did not change after sintering. By observing the cross section of the anode ridge structures after sintering, it was confirmed that the interfacial areas were extended by $25 \%$ in P75, $47 \%$ in P78, and 285\% in P80. In summary, the increase in the solid loading in the anode paste led to the high aspect ratio of the ridge structures, thereby the large extension of the interfacial area was obtained.

\section{Acknowledgments}

This work was supported by Japan Science and Technology Agency (JST) under Collaborative Research Based on Adaptable and Seamless Technology Transfer Program through Target-driven R\&D (A-STEP) Grant Number JPMJTS1613. Also, this work was supported by JSPS KAKENHI Grant Number 19K04216.

\section{References}

1. H. Iwai, A. Kuroyanagi, M. Saito, A. Konno, H. Yoshida, T. Yamada, S, Nishiwaki, J. Power Sources, 196(7), 3485 (2011).

2. A. Konno, H. Iwai, K. Inuyama, A. Kuroyanagi, M. Saito, H. Yoshida, K. Kodani, K. Yoshikata, J. Power Sources, 196(1), 98 (2011).

3. A. Konno, H. Iwai, M. Saito, H. Yoshida, J. Power Sources, 196(18), 7442 (2011).

4. M. Kishimoto, M. Sasaki, H. Iwai, H. Yoshida, 13th European SOFC \& SOE Forum, 46 (2018).

5. H. Seo, H. Iwai, M. Kishimoto, C. Ding, M. Saito, H. Yoshida, Unpublished results.

6. F. Tsumori, Y. Tanaka, Y. Xu, T. Osada, H. Miura, Jpn. J. Applied Physics, 53, 65 (2014)

7. J.A. Cebollero, R. Lahoz, M.A. Laguna-Bercero, A. Larrea, J. Power Sources, 360, 336 (2017).

8. M. Brown, S. Primdah, M. Mogensen, J. Electrochem. Soc., 147(2), 475 (2000).

9. K. Yuan, Y. Ji, J. N. Chung, J. Power Sources, 194(2), 908 (2009).

10. M. Kishimoto, H. Iwai, M. Saito, H. Yoshida, ECS Trans., 57(1), 2515 (2013).

11. A. Konno, H. Iwai, M. Saito, H. Yoshida, Heat Transfer Asian Research, 41, 700 (2012)

12. W. H. Herschel, R. Bulkley, Kolloid Z, 39291 (1926). 
13. R. P. Chhabra, Rheology of Complex Fluids, p. 3, Springer, New York (2010). 